\title{
Entrevista com Morgada Cunha
}

\section{Luciane Silveira Soares*}

Resumo

Morgada Assumpção Cunha relata sobre a criação do Grupo de Dança da UFRGS na Escola de Educação Física, grupo do qual foi diretora e coreógrafa de 1976 (ano de início) a 1983 (ano de término). O Grupo nasce no mesmo período que outros grupos de dança contemporânea de Porto Alegre, por um desejo da professora Morgada em estabelecer um trabaIho como coreógrafa e das alunas do curso de educação física em ter um grupo de dança na universidade. A entrevista integra o Projeto Garimpando Memórias, desenvolvido pelo Centro de Memória do Esporte, da Escola de Educação Física da UFRGS. $O$ depoimento a seguir integra um conjunto de entrevistas realizadas para minha dissertação de mestrado com a professora e ex-integrantes do grupo.

Palavras-chave: Dança. História da dança.

\begin{abstract}
Morgada Assumption Cunha reports on the creation of the Dance Group at UFRGS School of Physical Education, which was the group director and choreographer of 1976 (starting year) to 1983 (year end). The group was born in the same period that other contemporary dance groups of Porto Alegre, by a desire to establish Morgada teacher's work as a choreographer and students of physical education course to have a dance group at the university. The interview is part of the Digging Memories Project, developed by the Center for Memory of Sports, School of Physical Education at UFRGS. The following statement includes a set of interviews for my dissertation with Professor and former members of the group.
\end{abstract}

Keywords: Dance. Dance history. 
Luciane Soares - A pergunta com a qual eu quero iniciar a nossa entrevista é: por que criar um grupo de dança dentro da Universidade ${ }^{1}$ ?

Morgada Cunha ${ }^{2}$ - Pela vontade de desenvolver um trabalho de ordem coreográfica que sempre foi o meu forte; não eram as aulas e sim a criação de coreografia. Então eu dei tratos à bola. Até para acomodar uma situação: eu tinha 40 horas e depois que me aposentei do Estado eu pedi Dedicação Exclusiva. Então era necessário preencher aquele tempo que sobrava da graduação, pois, não eram muitas turmas na graduação naquele tempo. Eu realizava como trabalho de extensão. Este projeto foi muito bem recebido na Pró-Reitoria de Extensão, não me lembro quem era o Reitor naquela época. Eu passei por uns quatro Pró-Reitores de Extensão, foram sempre muito receptivos. O professor Preussler ${ }^{3}$ foi o único que não estava totalmente de acordo com o projeto, era meio contra a história porque toda hora eu solicitava coisas, mas os outros todos foram excelentes. Na época que foi um movimento cultural na UFRGS nós tivemos espaço, eu fiz vários trabalhos onde o grupo se apresentou. Então, uniu-se o útil ao agradável, na verdade é isso: eu me esforcei, fui falar com o Reitor e ele disse tudo bem. A ESEF me cedeu a sala com luz, com vestiário com toda a infra e eu complementei o meu horário que precisava. $\mathrm{E}$, mesmo que eu não tivesse horário, eu faria novamente porque foi um período muito bom, foram sete anos e meio de um trabalho, às vezes quatro vezes por semana... Elas já estavam com um aprimoramento técnico muito bom, então em função disso que o grupo foi fundado em agosto de 1976.

Luciane Soares - Quem eram as alunas?

Morgada Cunha - Algumas eram da ESEF, outras que ficaram sabendo de outras faculdades vieram e a gente fazia teste de aptidão. Eu sempre fazia um teste para ver se a pessoa tinha, ao menos, uma inclinação para a dança, porque não adianta colocar um monte de gente que não ia resultar em nada. Teve uma época que nós chegamos a ter 32 pessoas, mas, houve uma seleção natural, as pessoas não aguentaram o tirão e viram que não era o que elas queriam ou queriam, mas não podiam. Então eu comecei a trabalhar com 15, 16 pessoas.

Luciane Soares - Foi no inicio que tiveram essas 32 pessoas?

Morgada Cunha - Foi no segundo ano, em 1977. Nós espalhamos pelas aulas a divulgação que estávamos fazendo testes para o Grupo de Dança e o pessoal veio e fizeram testes. Faziam testes de ritmo, de improviso para ver quem tinha mesmo aptidão. A grande maioria nunca tinha estudado dança, uma ou outra apenas. Havia a Ana Lucia Medaglia ${ }^{4}$, mas ela não integrou o grupo como bailarina, ela foi contratada par dar aulas de clássico. Ela era muito boa professora, tinha uma técnica esplêndida. Então nós fazíamos o clás- 
sico, a Martha ${ }^{5}$ com o Adans Marroquín ${ }^{6}$ que está comigo novamente, é um excelente professor e amigo, gosta demais do grupo. E assim foi feito o Grupo da UFRGS. Teve uma sessão solene no dia 06 de agosto, quando começava o segundo semestre e a professora Quintina estava junto comigo. Colocamos uma mesa com toalha branca e flores no meio para inaugurar oficialmente 0 grupo; não se tirou foto disto, mas, aconteceu, a gente não tinha o hábito, nem tão pouco pensávamos que ia durar mais do que 2 anos, no final durou 7.

Luciane Soares - Em função do quê vinha nesta perspectiva de que duraria pouco?

Morgada Cunha - Na verdade, como não era um grupo profissional, eu não podia exigir muitas coisas delas, então o horário, por exemplo, que foi uma das causas da nossa separação, é que chegou um ponto em que elas estavam tecnicamente bastante boas, não como profissionais, mas amadoras de alto nível. Elas estavam dançando muitíssimo bem e isso requeria o quê? mais treino, mais aulas, mais ensaios e elas não quiseram e eu não ia estacionar no mesmo patamar que vocês estavam. Vamos parar! Eu brigava com elas exigindo mais aulas e aí nos separamos e agora, vinte e oito anos depois, elas resolveram me chamar novamente, acho que elas ficaram com medo de eu "bater as botas".

Luciane Soares - Como eram divididas as aulas e os ensaios do grupo?

Morgada Cunha - Nós tínhamos uma hora de aula porque eram três horas. A gente era bem mais jovem e aguentava, às vezes 3 horas e meia. Então, a primeira hora no dia de clássico, era barra, era centro, adágio, variações, para elas terem aquela postura que só o clássico dá. Na outra vez da semana fazíamos o contemporâneo, fazia Martha que o Adans tomava conta desta parte e mais uma terceira vez por semana, isso era sempre, mas nós ensaiávamos sábado também, mas com um aquecimento rápido e entrávamos no ensaio, fazíamos um trabalho expressionista também porque eu não concebo dança sem que a fisionomia, ou mesmo a participação corporal, que não dê o recado. Essa coisa andrógina não tem uma definição, as pessoas parecem manequins frios, extraterrestres.

Então eu colocava o pessoal no espelho para treinar a fisionomia, elas morriam de rir das minhas aulas por isso. Elas se confrontavam no espelho, eu dizia:"Tu gosta da tua cara assim?"; "Está parecido como que eu te pedi?"

Então se trabalhou muito a parte expressionista não só de fisionomia, mas, principalmente, porque as pessoas tem vergonha de externar fisionomicamente alguma coisa relativa ao enredo do que esta fazendo. Faz no corpo, mas, no rosto fica igual, é como no teatro, tem que mexer o rosto, tem que fazer caras e bocas e expressão de mãos. Quase sempre meus trabalhos tinham enredo, nem todos, mas em geral eu primava por ter um enredo, então tinha que acompanhar aquele por inteiro e não pela metade. Nosso trabalho era basicamente esse.

\footnotetext{
5 Referência ao estilo de Martha Graham de dança moderna estruturada entre os anos 20 e 30 do século XX na América do Norte

6 Adans Iraheta Marroquín: Ex integrante, professor e coreógrafo do Grupo de Dança da UFRGS.
} 
Luciane Soares - A primeira apresentação do grupo foi no mesmo ano da criação?

Morgada Cunha - Não, foi no final de 1977. Eu tinha que preparar os corpos em primeiro lugar, elas dançavam, mas não eram técnicas e continuaram não sendo após o espetáculo. Tornaram-se bailarinas, mas sem grande técnica ainda. Elas dançavam, tinham o embalo da dança. O primeiro espetáculo foi um divertissement, foi com números isolados com um pequeno enredo cada, um título que dizia alguma coisa. Se fez vários trabalhos uns onze para fazer 1 hora de trabalho.

Luciane Soares - Ele foi intitulado como divertissement mesmo? Ou tinha um nome especifico?

Morgada Cunha - Não me lembro. Acho que foi divertissement mesmo, ainda tive a petulância de colocar o nome em francês (risos), porque eu era oriunda de uma escola de ballet. Meu forte era a dança clássica depois que eu derivei e fui fazer outros estilos. Então eu acho que era esse nome mesmo. Depois nós levamos também Histórias Infantis onde tinha o Gato de Botas, tinha Alice no País das Maravilhas, tudo assim em pequenas entradas. Entrava, fazia mais ou menos uma coisa meio crítica, saía e já vinha a outra historinha. Tiveram várias historinhas que contamos em forma de pocket, rapidinho. $\mathrm{E}$ foi muito bonitinho, a Bela Adormecida, os Três Porquinhos... E mandamos fazer roupas, tudo especial, os Porquinhos eram enormes, com máscaras, acho até que foi aquele rapaz do teatro o Sérgio llha ${ }^{7}$ que fez as máscaras, ficou muito bonito.

As roupas a gente fazia assim: a Pro-Reitoria que fomentava, via trabaIhos de extensão tinha uma verba da FUNARTE ${ }^{8}$, hoje talvez fossem mil reais por ano. Como não tínhamos de onde tirar a gente achava maravilhoso, eu prestava conta de tudo, eu comprava os tecidos e no ano depois a gente ia reformando. Sempre que podia eu ia estocando as fazendas para os próximos anos, eu era assalariada, mas eu comprava, nem sabia para que eu ia usar. Nós tínhamos uma costureira, a mãe da Zelira Eichemberg que foi professora na ESEF, que fazia os figurinos. As malhas eu mandava fazer numa malharia eram de linha, ali no Bairro Glória, o primeiro nome eu não me lembro, acho que Lourdes Valduga ${ }^{9}$, ela fazia as minhas malhas de aula, porque eu gostava de desfilar (risos) fazia desenhos na malhas e todos queriam saber onde eu comprava.

Luciane Soares - A ideia inicial era de seguir na linha clássica ou de que forma a senhora caracterizaria o Grupo de Dança da UFRGS? Qual estilo?

Morgada Cunha - Dança contemporânea. Elas não poderiam dançar clássico, elas faziam aula de clássico para aprimorar gestos e posturas, mas sempre foi intenção fazer dança contemporânea. Todo mundo deve e pode fazer clássico, mas não é para todo mundo se apresentar. Além do que estava

7 Ator que também atuou como figurinista para o Grupo de Dança da UFRGS.

8 Fundação Nacional de Artes. http://www.funarte.gov.br/a-funarte/

9 Nome sujeito à confirmação 
um boom em dança contemporânea em Porto Alegre.

Luciane Soares - Então! O que acontecia na cidade nessa época?

Morgada Cunha - Olha! A Cecy ${ }^{10}$ formou um grupo um ano depois de mim, o Choreo ${ }^{11}$. Usava-se muito Grupo hoje preferem chamar de Companhia, mas isso é coisa profissional... A Lenita ${ }^{12}$ anos depois montou o Imbahá ${ }^{13}$ onde eu também coreografei anos mais tarde. A Denise Chemale ${ }^{14}$ tinha o Geração Grupo de Dança e nós o grupo da UFRGS. A Tony formou o Phoenix ${ }^{15}$, entre 70 e 80 foi o boom dos grupos de dança em Porto Alegre. E todo mundo fazia contemporâneo.

Quem trouxe o contemporâneo para Porto Alegre, não saberia dizer, foi uma coisa meio simultânea os grupos vinham se preparando. Quando chegou 1980 tudo começou; tinha a Eva Schul ${ }^{16}$ e a ela foi mais quem introduziu isso. Assisti ao espetáculo muito bom trabalho, mas era mais para o lado do teatro dança. A Tony ${ }^{17}$ tinha um grupo que mudava de nome toda hora até que montou o Phoenix, mas foi depois de mim, da Eva e da Cecy. A Lenita com o Imbahá contratou coreógrafos importantes para o grupo dela. Chamou até o Arrieta $^{18}$ para fazer uma coreografia lindíssima. Depois foi que o grupo acabou como de fato todos acabaram, uns duraram mais ou menos tempo, mas todos daquela época acabaram.

Luciane Soares - E técnica em dança contemporânea como era trabalho dentro do grupo?

Morgada Cunha - Era o estilo da Martha que o Adans trabalhava, ele era especialista nisso. Ele foi bailarino em San Salvador, a capital de El Salvador. Ele veio fazer o curso de Física e hoje é professor de Física em Rio Grande ${ }^{19}$, em uma faculdade particular. Ele apareceu no grupo muito humilde para trabalhar conosco, ele é uma pessoa espetacular, um grande amigo meu, a gente sente que ele quer muito bem o grupo, e olha que passaram quase trinta anos.

No Grupo ele dava aulas da técnica de Martha Graham, então, nós tínhamos esta variação. Eu dava aulas de clássico, mas depois eu cansei, pois dava aulas na graduação, no Grupo e fazia as coreografias, aquilo estava pesando para mim, foi então que chamei a Ana Lucia Medalha, uma excelente bailarina. Ela veio para dar continuidade ao trabalho que eu parei de fazer. Ela e o Adans eram pagos por mim, os bailarinos não recebiam nada. A gente desenvolvia o trabalho no amor porque não tínhamos dinheiro suficiente. O Arman-

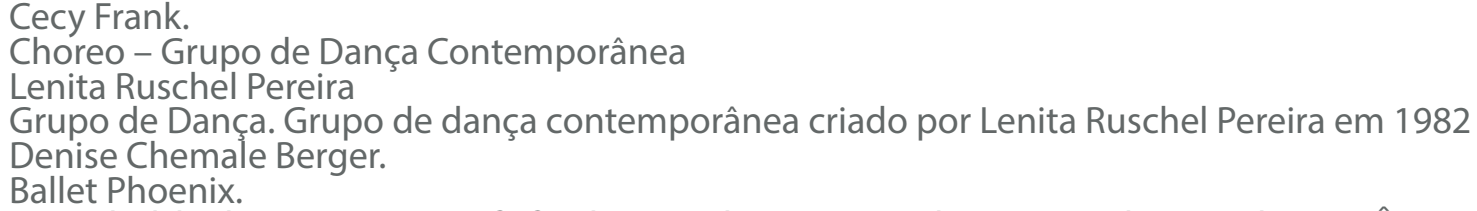

Eva Schul, bailarina e coreógrafa foi diretora do Grupo Mudança e atualmente dirige a Ânima Cia. de Dan- 
do Duarte veio para fazer uma coreografia e foi pago por mim.

A nossa ida para São Paulo, quando fomos dançar no ENDA ${ }^{20}$, as passagens de ônibus da gurizada eu paguei do meu bolso. Foram 15 passagens de ida e volta. Foi um convite do marido ${ }^{21}$ da Hulda Bittencourt que era sócio da Associação de Dança de São Paulo. Naquele tempo a Maria Pia Finócchio era Presidente, era e é tão organizada, as coisas em São Paulo andam em matéria de dança, impressionante. São Paulo sempre foi uma expressão em dança, principalmente em se tratando de grupos, mais que o Rio de Janeiro.

Foi maravilhoso. Nós ficamos nos alojamentos do Cisne $\mathrm{Negro}^{22}$, e fizemos a apresentação da Rapsódia Felina. Era super teatral e o pessoal adorou... Um teatro de costumes, não me lembro nem sei por que fomos convidados mas o convite partiu da Hulda para representar o Rio Grande do Sul. Nos apresentamos em dois atos no Teatro São Pedro de lá. Tivemos que fazer o cenário lá porque não tínhamos como levar daqui. das?

Luciane Soares - Quanto às apresentações, em que locais eram realiza-

Morgada Cunha - Nós fazíamos a maioria dos espetáculos dentro da Reitoria pela facilidade. Era gratuito e a gente não cobrava ingresso. Tínhamos casa hiper lotada sempre porque tinha um programa em que os alunos assistiam de graça aos espetáculos oferecidos, era o UNIARTE ${ }^{23}$.

Luciane Soares - Ocupavam também outros teatros da cidade?

Morgada Cunha - Sempre a convite, ou da Associação, a ASGADAN ${ }^{24}$, que dançamos na Assembleia Legislativa, ou a convite no Teatro de Câmara, no Instituto de Artes da UFRGS. Nós fizemos vários teatros, mas sempre a convite. Também tinha a seguinte situação: na comemoração dos 104 anos do Leopoldina Juvenil ${ }^{25}$, nos convidaram para fazer a dança antes do bolo, os alunos eram os contatos para os convites. Na Redenção ${ }^{26}$ junto ao grupo do Professor Rolla ${ }^{27}$, então eram quase sempre a convite, pois não tínhamos como alugar um espaço para apresentar. mente?

Luciane Soares - O Grupo era um projeto de extensão renovado anual-

Morgada Cunha - Sim. Anualmente e sempre com muita recepção da Pró-Reitoria. Menos com o professor Preussler, como eu já te falei. Quando eu montei o espetáculo "A Colméia" eu precisei da marcenaria da Universidade, ele disse que eu tinha que acabar com o Grupo e eu disse: "Agora que elas estão boas o senhor quer que eu termine?" Mas nem aqui e em lugar nenhum, fui bem desaforada e perguntei se ele não estava ali para quebrar os

20 Encontro Nacional de Dança.

21 Edmundo Rodrigues Bittencourt, esposo de Hulda Bittencourt, fundadores do da Cisne negro Cia. de

23 Projeto da Pró-Reitoria de Extensão da UFRGS.

24 Associação Gaúcha de Dança

25 Associação Leopoldina Juvenil.

26 Nome popular atribuído ao Parque Farroupilha.

27

João Luiz Rolla. 
galhos. E aí ele não me deu resposta eu fui direto a Diretoria que comandava a marcenaria. Eles contrataram um arquiteto que desenhou o projeto todo que tinha que ser feito por um engenheiro ou um arquiteto, pois tinha que suportar o peso do corpo em cima, dentro e dos lados. Então ele fez uma armação de ferro primeiro e depois cobriu com madeira os favos, somente gente com técnica poderia fazer, não podia ser feito de qualquer jeito. Eu fui furando esquemas, batendo de porta em porta.

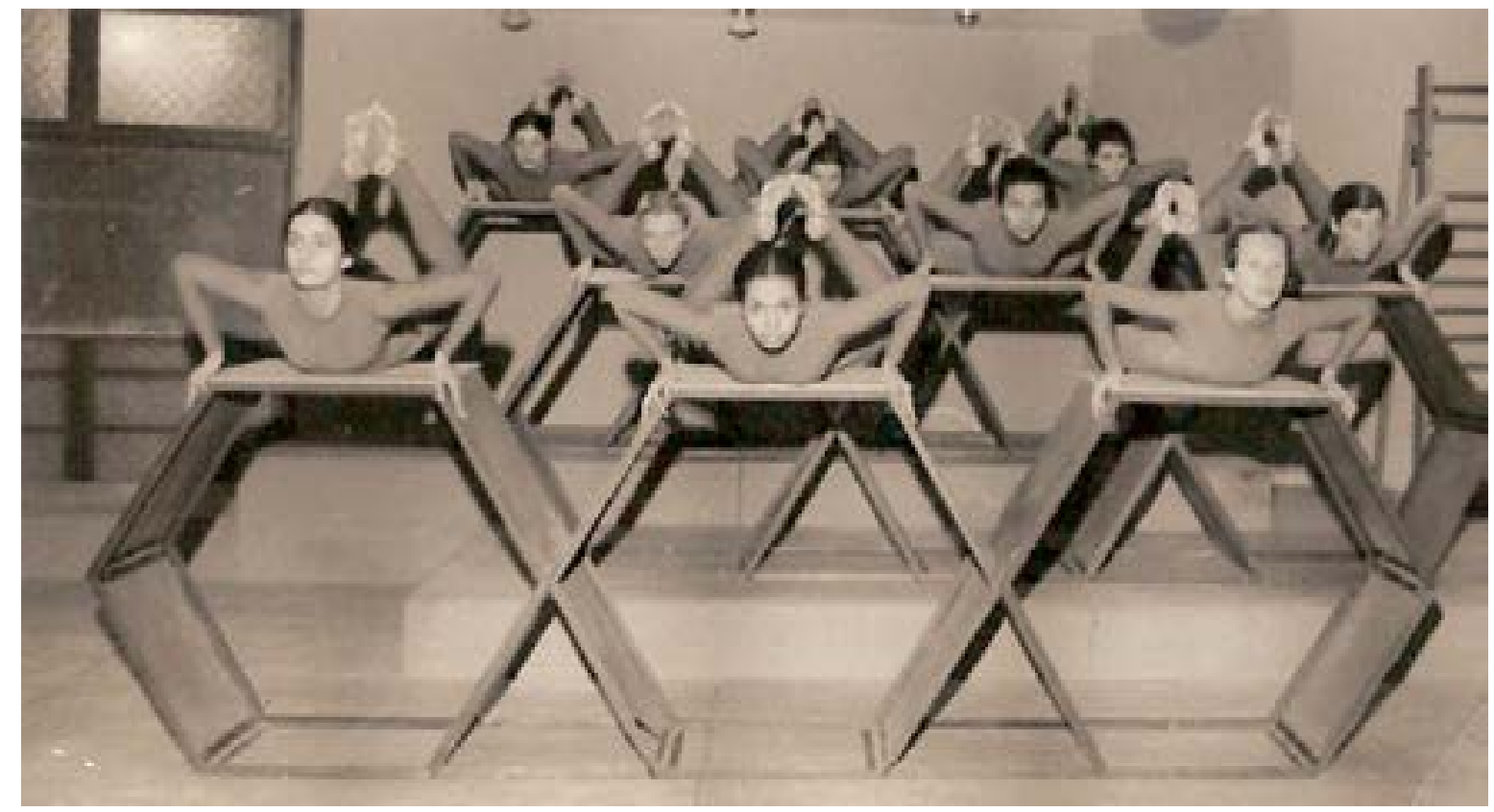

Figura 1 - Coreografia "A Colméia" (1981) - Grupo de Dança da UFRGS

Fonte: Centro de Memória do Esportes

Luciane Soares - O repertório coreográfico foi crescendo conforme a disposição técnica dos bailarinos?

Morgada Cunha - Sim. No início eram pequenos números para formar uma hora de espetáculo. Eu fui através das pequenas apresentações desenvolvendo a criatividade; se podemos fazer pequenos quem sabe podemos fazer coisas maiores? Eu fui aumentando os tempos de duração. O meu crescimento como coreógrafa tinha que ser conforme as potencialidades do Grupo, não adiantava mais ou menos que ficaria até feio. Foi de acordo com elas, não eram altamente técnicas, mas tinham um amor, uma coisa vibrante pela dança, que elas manifestavam, então, eu achava que o Grupo era bastante bom, mas eu sou suspeita para falar do trabalho que eu fiz.

Luciane Soares - Em algum momento os bailarinos chegaram a participar do processo de criação coreográfica?

Morgada Cunha - Sempre! Até hoje nos meus trabalhos os bailarinos participam, sempre tem um momento de criação do Grupo, a coreografia não pode ficar com uma digital única. Isso diversifica o trabalho, fica bonito, é bom para o bailarino. Comigo eles sempre foram "criados" dentro deste regime de criatividade. Eu não primo por técnica, eu primo pela originalidade da temática e em cima disso tem que se desenvolver tudo. Eu gosto de fazer 
coisas originais que ainda não foram feitas ou vistas de outra forma totalmente diferente, então, coloco a minha digital ali, é assim que eu gosto. É contemporâneo, mas não segue estes trâmites enlouquecidos que eu nem tenho uma ligação maior. Eu não estudei isso, então, não vou me arvorar no que eu não tenho conhecimento mesmo que eu ache que até funcione. Eu gosto assim: quem vai assistir meu trabalho não precisa ler o programa para saber do que trata a obra, eu entrego tudo mastigadinho, as pessoas acham isso antigo, mas não me importa. Se eu tenho uma plateia olhando, não cochila, está atenta, está bom. Eu quero que a pessoa se divirta com o que está vendo mesmo que esteja apresentando uma tragédia, mas se está se deleitando com o todo, podendo fazer a sua leitura. A dança para mim é isto, o momento que tu te libertas e olhas aquilo de uma forma estética. Eu sou muito dada à estética, às formas que necessariamente não precisam ter altas técnicas, no simples, no liso no clean, mas que tem um conteúdo que pega.

Luciane Soares - Na época vocês tinham notícia de outro grupo que funcionasse dentro de uma universidade?

Morgada Cunha - Não. Na época não. Logo depois que eu saí da Universidade foi formado um grupo de folclore, a moça era médica e era aluna da Cristina Fragoso aqui em Porto Alegre, mas eu nunca assisti o trabalho dela. Acho que era Grupo Folclórico da UFRGS algo do tipo. Eu não sei se ele teve muita visibilidade dentro da universidade ou fora como o Os Gaúchos ${ }^{28}$ por exemplo.

Luciane Soares - Depois então de sete anos, o que ocasionou o término do grupo?

Morgada Cunha - Foi a minha exigência, uma das causas. A outra foi que elas já estavam começando a trabalhar, umas estavam em final de curso e já estavam trabalhando em academias ou já tinham sua própria academia, enfim. A minha exigência de mais horas de trabalho, eu endurecia com elas, pois chegou a um ponto em que trancou, eu queria desenvolver mais, fazer coisas mais trabalhadas e não dava. Elas tinham potencialidades para isso, mas não tinham tempo, daí eu não podia continuar, então, foi desgastando, eu já estava cansada ainda faltava tempo para eu me aposentar e também tinha meus filhos e esse lance de correr atrás deles para saber onde andavam. Então resolvemos parar. No início eu senti um pouco porque aquilo era quase como um filho, era outro filho que eu tinha para cuidar, mas eu verifiquei que era bem menos trabalho para mim e deixei. Assim, passaram-se 28 anos e agora elas resolveram me procurar para dançar novamente e estamos iniciando um novo trabalho para dançarmos em 2012.

Luciane Soares - Muito obrigada professora Morgada

Morgada Cunha - Muito Obrigada a ti também pelo teu trabalho. 
Cena 14

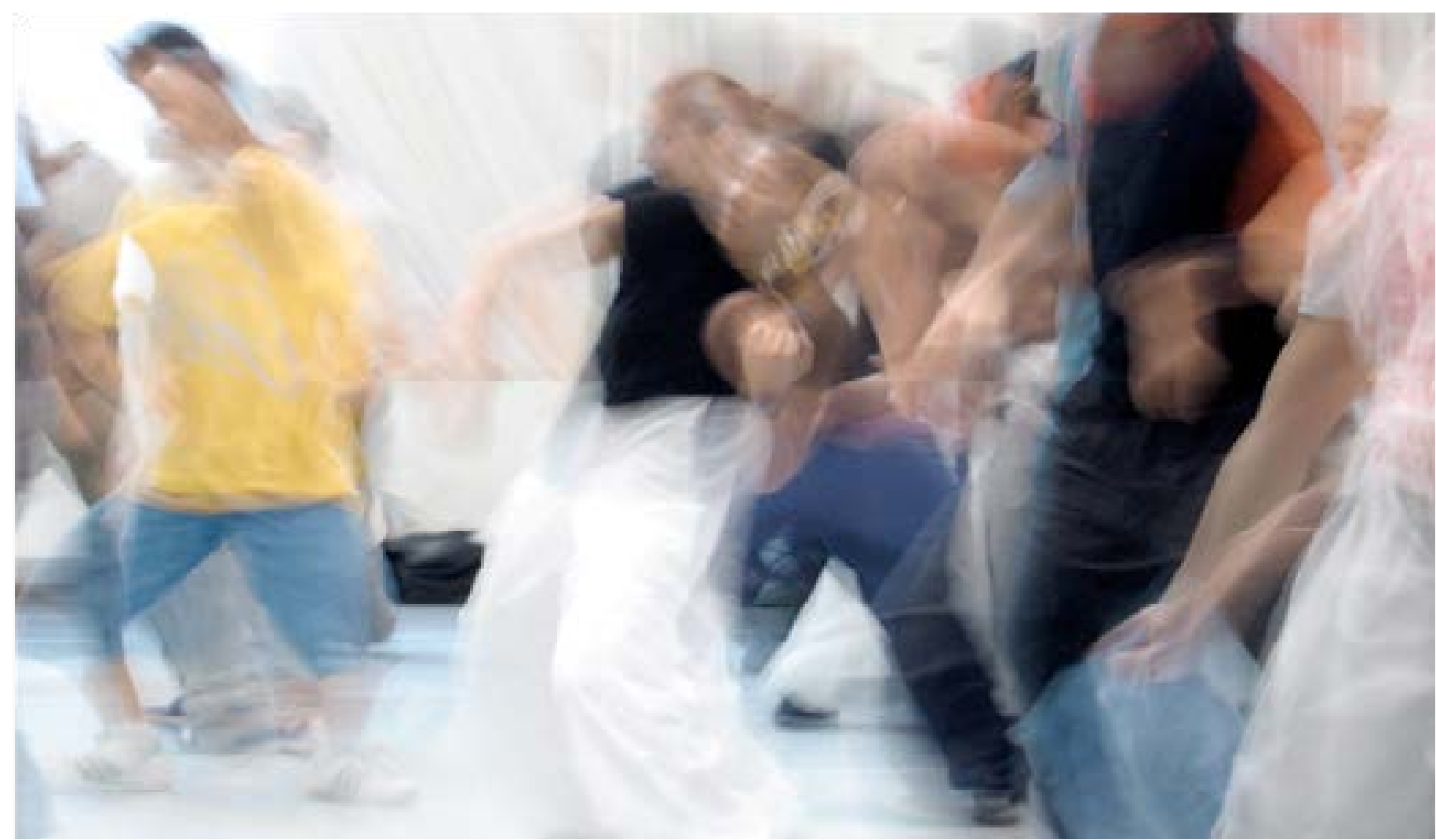

